\title{
DU RETOUR D'ULYSSE À ARGOS OU LA SPATIALITÉ IDÉALE SELON MÉNÉLAS
}

\author{
IDEAL SPATIALITY ACCORDING TO MENELAUS: \\ ODYSSEUS BACK TO ARGOS
}

\author{
FRANCIS LARRAN \\ Lycée Martin Luther King Bussy Saint-Georges (France) \\ Rattaché à $A r S c A n$ \\ francislarran77@gmail.com \\ ORCID: 0000-0002-4559-3554
}

DOI: $10.1387 /$ veleia.16831

Extrait: Poème sur la distance, l'Odyssée interroge les notions du proche et du lointain, de la dispersion et du regroupement tout comme celles du contact topographique et du contact topologique, en un temps où les aristocraties grecques sont prises dans un jeu complexe d'échelles identitaires. Doivent-elles d'abord s'enraciner, à l'échelle locale, dans un rapport de proximité immédiate avec les autres membres de la polis? Se bâtissent-elles au contraire, à l'échelle de la Grèce continentale ou bien encore à celle du monde connu, dans le cadre d'un «web» constitué de cités connectées? Chercher la proximité immédiate avec Ulysse, un héros né sur la lointaine Ithaque, c'est sans doute, pour Ménélas, tenter de concilier, dans un idéal aristocratique impossible, les deux spatialités concurrentes du haut archaïsme.

Mots clefs: Ulysse, géographie, distance, proximité, lointain, réseau, espace, spatialité, Odyssée.

Abstract: As a poem focusing on the notion of distance, the Odyssey elaborates on the concepts of proximity and distance, dispersion and concentration, topographical and topological contacts at a time in which archaic aristocracies were involved in a complex interplay of nuanced identities. First, at the local level, should they live close to the other members of the polis? Second, on a more general level, should they look at the continental Greece or, alternatively, to the known world, within a network of connected cities? For Menelaus, seeking to be close to Odysseus, a hero born in the distant Ithaca, means conciliating two antagonist spatialities in an aristocratic and archaic utopia.

Key words: Odysseus, geography, distance, proximity, network, space, spatiality, Odyssey.

Recibido : 12-06-2015

Informado : 27-11-2015

Definitivo : 09-12-2015

Après le sac de Troie, Ulysse aurait pu s'établir à Argos plutôt que revenir à Ithaque! Aussi surprenante soit-elle pour le lecteur de l'Odyssée habitué à entendre le fils de Laërte pleurer son impossible retour dans sa terre patrie ${ }^{1}$, l'idée d'installer Ulysse et les siens près de Sparte relève, aux

1 Par exemple: Homère, Odyssée, I, 11-15, 56-59;

IV, 555-558; V, 7-20, 151-158, 215-224; VII, 222-

224; XIII, 250-252, 352-355. 
yeux de Ménélas, non seulement du possible mais encore d'un bonheur idéal à même de susciter la jalousie des dieux. Conçu avant de quitter le rivage troyen et présenté à Télémaque au chant IV de l'Odyssée, le projet est ainsi clairement défini par l'Atride: «Oh! Ciel! J'ai sous mon toit le fils de cet ami qui jadis, pour ma cause, affronta tant de luttes! Je m'étais bien promis, quand il viendrait chez moi, que nul des Achéens n'aurait meilleur accueil. Si le dieu de l'Olympe, le Zeus à la grand-voix, nous avait accordé de repasser, tous deux, la mer sur nos croiseurs, je voulais en Argos lui céder une ville, lui bâtir un manoir, le transplanter d'Ithaque avec ses biens, son fils, son peuple tout entier; j'aurais vidé pour eux quelqu'une des cités qui, dans le voisinage, ont reconnu ma loi, et nous aurions ici fréquenté l'un chez l'autre, sans que rien vînt troubler notre accord et nos joies, jusqu'au jour où la mort nous eût enveloppés dans son nuage d'ombre... Il a fallu qu'un dieu, m'enviant ce bonheur, ne privât du retour que lui, le malheureux!»².

Sans équivalent dans l'épopée homérique, le vœu de Ménélas n'a eu de cesse de questionner les spécialistes. Des études politiques classiques aux analyses à dominante littéraire sans oublier les commentaires économiques ou culturels, les voies de l'exégèse consacrée à ce passage s'ouvrent largement sans parvenir à un véritable consensus. A-t-on cherché à expliquer le projet de Ménélas à la lumière de comparaisons historiques archaïques (A. Fanta) ou médiévales (C. H. Whitman)? Aussitôt P. Carlier rappelle que la cession du territoire argien ici imaginée ressemble faussement à celles du monde féodal et qu' elle pourrait certes trouver son inspiration dans le développement des cités périèques, comme le suggère $\mathrm{A}$. Fanta, mais également dans bien d'autres fédérations politiques du haut archaïsme ${ }^{3}$. Préfère-t-on voir dans la proposition de Ménélas l'héritage d'une tradition pro-spartiate (P. Sauzeau), la marque de l'affirmation politique lacédémonienne après la disparition d'Agamemnon (G. C. Vlachos) ou bien encore l'expression de la gratitude d'un riche souverain envers un pauvre compagnon d'armes (J. V. Andreev, P. Karatives et O. Levaniouk) ${ }^{4}$ ? $\mathrm{M}$. Briand montre que le passage fonctionne, comme le reste du chant IV, sous le régime d'une ironie transformant Ménélas en un personnage contradictoire, doté de pouvoirs et de savoirs surhumains mais incapable de réaliser ses vœux 5 .

Le texte de l'Odyssée se plie, de toute façon, assez difficilement aux diverses interprétations proposées. Contre les tenants de l'avantage économique à s'implanter auprès de Ménélas, Télémaque refuse ainsi, par fidélité patriotique, de troquer les richesses de la vaste plaine d'Argos contre la pauvreté de sa rocheuse Ithaque ${ }^{6}$. À l'encontre des partisans d'une réplique politique de Ménélas au geste d'Agamemnon qui cherchait, dans l'Iliade, à se réconcilier Achille en lui offrant, avec leurs riches thémistes, sept villes peut-être situées sur le territoire lacédémonien ${ }^{7}$, il n'est question pour Ulysse ni de toucher de grasses recettes fiscales ni même véritablement de s'implanter dans le royaume d'Agamemnon. Confrontée à une épopée qui s'intéresse sans doute moins à la réalité géographique du monde qu'à la dimension morale de la spatialité héroïque, l'historiographie contemporaine pèche sans doute par excès de positivisme. Fictions à dissocier d'une parfaite réalité politique et institutionnelle que la communauté savante aimerait trop souvent lui voir refléter, l'Iliade et l'Odyssée ne se comprennent pas une carte à la main. La ville offerte par Ménélas à Ulysse n'est rard).

2 Homère, Odyssée, IV, 169-182 (traduction V. Bé-

3 Voir ici Whitman 1965, 45; Fanta 1882, 52 sq [avec Pausanias, IV, 14, 3] et Carlier 1984, 179.

4 Sauzeau 1998, 86 avec la scholie à Euripide, Oreste, 46; Vlachos 1974, 274-278; Andreev 1979, 365 sq; Karavites 1992, 55 et Levaniouk 2011, 58-59.
5 Briand 1998, 42.

6 Homère, Odyssée, IV, 600-608 avec, par exemple, Vilatte 1991, 37-38; Karavites 1992, 54.

7 Homère, Iliade, IX, 149-156 avec Vlachos 1974, 278-280, Heubeck, West et Hainsworth 1990, 204205 et Sergent 1994, 103-109. 
pas plus à localiser dans un espace clairement circonscrit par un géographe surplombant le monde qu'Argos à ancrer définitivement dans un territoire aux frontières fixes et nettes ${ }^{8}$. Insaisissable, mouvant et opaque, l'espace homérique doit être accepté tel qu'il se présente pour être compris. Plutôt qu'une vaine réalité économique, politique et institutionnelle, il faudra ainsi, fidèle à la lettre du texte, se contenter de décrypter l'unique volonté de Ménélas: vivre auprès d'Ulysse pour le restant de son existence.

La géographie telle qu'elle est aujourd'hui pensée par M. Lussault et J. Lévy9 pourrait, dans cette perspective, contribuer à renouveler l'interprétation historiographique des vers 169-182 du chant IV de l'Odyssée. Loin des postulats vidaliens de V. Bérard qui offraient une lecture réaliste et atemporelle de lieux odysséens à juxtaposer sur une carte topographique, il faudra accepter de soustraire au monde réel l'espace imaginé par Ménélas ${ }^{10}$. Conscient de l'apport mais aussi des limites de la géographie culturelle d'A. Ballabriga qui s'intéressait à la représentation des espaces homériques selon leur seul emplacement dans le monde, il faudra privilégier, dans le sillage de l'approche proxémique de $\mathrm{D}$. Lateiner, une géographie multiscalaire des relations pour comprendre le lien de proximité avec Ulysse souhaité par Ménélas ${ }^{11}$. Bien plus que la localisation précise d'Ulysse et des siens à Argos, c'est ainsi la distance idéale à établir entre les deux héros qu'il faut passer au crible d'une critique certes nourrie au précepte d'Aristarque mais toujours consciente de la nécessité de la mise en perspective historique. Si Homère est bien à comprendre d'après Homère comme le préconise l'érudit alexandrin, l'Iliade et l'Odyssée n'en demeurent pas moins des produits du haut archaïsme et résonnent, à ce titre, des préoccupations de leur temps. Contemporaine probable de l'affirmation de la cité, des synoecismes comme de l'essaimage des Grecs en Méditerranée lors de la "première colonisation archaïque»" ${ }^{12}$, l'épopée homérique cherche sans doute à répondre, avec la proximité idéale proposée par Ménélas, aux inquiétudes provoquées par ces mêmes mouvements de recomposition des spatialités. Poème sur la distance, l'Odyssée interroge effectivement les notions du proche et du lointain, de la dispersion et du regroupement tout comme celles du contact topographique (entre espaces contigus) et du contact topologique (entre espaces connectés), en un temps où les aristocraties grecques sont prises dans un jeu complexe d'échelles identitaires. Doivent-elles d'abord s'enraciner, à l'échelle locale, dans un rapport de proximité immédiate avec les autres membres de la polis? Se bâtissent-elles au contraire, à l'échelle de la Grèce continentale ou bien encore à celle du monde connu, dans le cadre d'un «web» constitué de cités connectées ${ }^{13}$ ? Chercher la proximité immédiate avec un héros né sur la lointaine Ithaque, c'est sans doute, pour Ménélas, tenter de concilier, dans un idéal aristocratique impossible, les deux spatialités concurrentes du haut archaïsme.

8 Sur la localisation imprécise et mouvante d'Argos dans l'épopée homérique, consulter Wathelet 1992 et Sauzeau 2005.

9 Voir par exemple Lévy et Lussault 2000 ainsi que Lussault 2007.

10 Par exemple Bérard 1971 avec Rabau 2005 et Calame 2007.

11 Respectivement Ballabriga 1986 et 1998; Lateiner 1992.
12 Sur les débats historiographiques consacrés à la pertinence du terme "colonisation» pour désigner le mouvement diasporique des Grecs archaïques, consulter notamment Osborne 1998 ainsi que la synthèse proposée par Schwentzel 2012, 15-20.

13 Sur l'importance des réseaux dans la construction identitaire du monde grec, voir Malkin 2005, 56-73. Sur la mise en réseau du monde méditerranéen ancien, voir de façon plus générale: Horden et Purcell 2000 et Broodbank 2013. 


\section{Ulysse au contact de MÉnélas ou la proximité topographique comme matrice DE LA SOCIÉTÉ HOMÉRIQUE}

L'intention de Ménélas est claire: Ulysse devra s'établir avec les siens suffisamment près de Sparte pour maintenir entre les deux compagnons des contacts concrets et fréquents. Elle reste attendue dans un monde homérique qui se vit, se pense et se réalise d'abord dans le contact topographique, quelle que soit l'échelle d'étude considérée.

Être $a \mathrm{mi}^{14}$, c'est en effet entretenir une relation de proximité constante. En temps de guerre, il faut partager, côte-à-côte, les moments de repos au campement, les déplacements en char comme les heures de combat au-devant des lignes ennemies. En temps de paix, il s'agit encore, à l'instar d'Ulysse et de ses amis d'enfance ou de Ménélas et de son compagnon-écuyer Étéôneus, d'habiter suffisamment près les uns des autres pour entretenir des relations quotidiennes, régulièrement concrétisées et affichées lors des festins ${ }^{15}$. Pris dans de telles relations de proximité, les amis ne font pas autrement que les autres cercles de sociabilité de l'épopée homérique qui n'ont vocation ni à se mélanger ni à éclater. Toujours respectueux des barrières sociales ${ }^{16}$, les gueux doivent rester avec les gueux, les nobles aux côtés des nobles et les peuples toujours ensemble ${ }^{17}$. Dans l'Odyssée, la prime revient surtout à l'oikos en mesure de tenir ses membres dans le lien indéfectible de la relation spatiale quotidienne. Les fils auprès de leur père, l'épouse aux côtés de son mari, la maîtresse en compagnie de ses servantes dans chacune de leurs activités et à chacun des moments de leur existence ${ }^{18}$ : l'existence idéale dans l'Odyssée est bien de celles qui permettent de vivre et de mourir auprès de ses proches tout comme de ses $l a o i^{19}$.

La configuration spatiale des différentes communautés homériques est directement conditionnée par cette logique de proximité. Pour assurer à chacun la possibilité d'entrer en contact avec l'individu moteur de la communauté, la répartition circulaire prévaut à chaque instant. À l'instar de l'espace imaginé par Ménélas qui voit Ulysse et les siens s'implanter dans une des villes qui entourent (perinaietaousi) Sparte, le monde homérique se présente comme une société écume composée d'une multitude de cellules polarisées, de taille variable et toujours liées les unes aux autres. Les cercles formés à l'occasion du combat, des funérailles, de l'assemblée, des récitations poétiques, de la vie quotidienne dans l'oikos et dans la cité comme des déplacements des héros ${ }^{20}$ constituent autant de particules mouvantes et s'englobant mutuellement ${ }^{21}$. Exemple pris parmi d'autres, l'oikos de Priam englobe ainsi l'ensemble de la société troyenne, composée d'une multitude d'oikoi particuliers tous reliés hiérarchiquement à l'oikos supérieur du roi. Il faut une audace toute particulière

14 Sur l'amitié et le compagnonnage homériques, consulter notamment: Jeanmaire 1939, 97-111; Finley 1977, 128 sq; Kakridis 1963; Carlier 1984, 181-182 et Naas 2000.

15 Par exemple Homère, Iliade, IX, 182-224, 656668; Odyssée, XV, 92-98, XVI, 255-259 et XVII, 68-69 avec Carlier 1984, 181-182.

16 Par exemple Homère, Odyssée, IV, 158-160; VI, 141-147, 286-288; XVIII, 327-334 et XXI, 285-294 avec Lévy 1995, 208.

17 Homère, Iliade, II, 362-363; Odyssée, XVI, $217-$ 218.

18 Par exemple: Homère, Iliade, VI, 242-250, 421423; Odyssée, III, 29-35, 386-387, 418-429 ; VI, 57-65, 180-185; XV, 99-105.
19 Homère, Odyssée, IV, 207-211; XI, 135-137; XXIII, 209-212, 283-284.

20 Pour le roi entouré par ses hommes et les autres chefs au moment du combat: Homère, Iliade, II, 445446, 474-483, III, 1-2, IV, 200-202, 210-212, XI, 56-60; Odyssée, XI, 409-417, XXIV, 24-34. Pour les héros entourés par leurs proches et leurs gens: Homère, Iliade, VI, 323-324, X, 150-152; Odyssée, III, 404-416, IV, 715-721, VI, 52-53, VII, 3-7, X, 409417, XI, 135-137, XXII, 114-115, XXIII, 283-284, XX, 62-67. L'orateur à l'assemblée comme l'aède dans le manoir se placent au centre: Homère, Odyssée, II, 35-38, V, 3-4, VIII, 65-66 et 472-473 (voir ici Ruzé 1997, 7-48).

21 Sur ce point V. Sebillotte Cuchet 2006, 153. 
pour rompre avec la logique de ce monde cellulaire, s'extraire de son cercle et affronter autrui. Tel est le cas des braves sous les murs de Troie, d'Ulysse parti seul au manoir de Circé mais aussi de Nausicaa qui, loin de la ville, se maintient hors du cercle de ses servantes (amphipoloisi) pour lui faire face ${ }^{22}$.

Les différents espaces de la société homérique comme celui imaginé par Ménélas ne sont que des composantes parmi d'autres d'un monde plus global régi selon les mêmes lois organisationnelles. Observé à la plus grande comme à la plus petite des échelles, le monde tel qu'il est pensé dans l'Iliade et l'Odyssée juxtapose lui aussi, tel un tissu connectif, les cellules qui le composent selon la logique du contact topographique. Autant l'efficacité d'un oikos, d'une troupe au combat ou d'un peuple réuni à l'assemblée implique une proximité spatiale entre leurs membres, autant la riche fécondité du jardin d'Alkinoos se lit dans l'entassement de ses fruits ${ }^{23}$. Entouré par le fleuve Océan ${ }^{24}$, le monde place, quant à lui, en son cœur l'espace achéen qui lui-même semble autocentré sur Argos. C'est encore selon une logique de contiguïté topographique qu'il prend sens: le Catalogue des Vaisseaux donne ainsi à lire le monde achéen en avançant de proche en proche ${ }^{25}$. C'est bien la vue d'un voyageur qui parcourt le monde à pied ou en navire ${ }^{26}$ et non le regard zénithal et omniscient du cartographe qui lui donne vie: d'abord, la Grèce centrale (Béotie, Locride, Phocide) puis, dans la continuité spatiale, l'Attique, le Péloponnèse (l'Argolide, Lacédémone, la Messénie, l'Arcadie, l'Elide), les îles de la côte Adriatique, le Nord de la Grèce (de l'Etolie à la Thessalie, avec une interruption pour passer par les îles de l'Egée).

Dans une société écume qui trouve ainsi sa cohérence dans le contact topographique, il faut éviter tout éloignement physique, souvent synonyme de dysfonctionnement. Telle est l'intention de Ménélas. Par le rapprochement avec l'oikos d'Ulysse, l'Atride entend conjurer une distance spatiale à même de troubler «leur accord et leurs joies». Pour en avoir fait l'expérience lors de son voyage dans la lointaine Ithaque avant la guerre de Troie ${ }^{27}$, Ménélas sait probablement que, dans un monde perçu comme infini, la parfaite maîtrise de la distance reste le seul apanage des dieux, qui infatigables et rapides comme les vents, se distinguent par leur pouvoir d'ubiquité28. Les voyages sur une terre sans bornes ou par-delà une mer immense riment à l'inverse, pour les hommes, avec une longue errance loin des leurs ${ }^{29}$, dans un espace fragmenté par la fragilité des communications et la perfidie des hommes des réseaux qui, pirates, commerçants et mendiants, nouent entre les lieux des relations bien incertaines ${ }^{30}$. Le lointain et son cortège de dangers parait toujours aux portes de son cercle de sociabilité. Sur terre, les déplacements même les plus courts sont craints. Entrer dans un manoir, aller à l'agora, se rendre puis traverser une ville étrangère ou même sim-

22 Homère, Odyssée, VI, 82-84 et 137-140; X, 271284.

${ }^{23}$ Notamment Homère, Iliade, II, 84-98, 469-473, 799-801; Odyssée, VII, 112-132.

${ }^{24}$ Homère, Iliade, I, 423-424; Odyssée, X, 508 avec Hésiode, Théogonie, 337, 776.

25 Homère, Iliade, II, 484-760 avec Visser 199, 1-52 pour un résumé des débats historiographiques sur la question.

${ }_{26}$ Notamment Homère, Iliade, II, 534-536, 625626 avec Odyssée, XXI, 344-348.

27 Homère, Odyssée, XXIV, 114-119.

28 Homère, Iliade, I, 357-365, II, 165-168, V, 368, 767-773, XV, 78-83; Odyssée, I, 84-86, 95-98, III, 231, V, 42-54, X, 570-574. Parents des dieux, les Phéaciens sont des passeurs infaillibles capables de franchir les distances rapidement et sans fatigue, grâce à leur connaissance du monde entier (Homère, Odyssée, VII, 318-328; VIII, 555-563 avec Ballabriga 1998, 199).

29 Un mois hors de son foyer est déjà considéré comme une souffrance difficile à supporter (Homère, Iliade, II, 289-298).

30 Par exemple Homère, Odyssée, III, 71-74 (= IX, 253-255), XIV, 115-127, 156-157, 372-389; XVIII, 1-9 et F. Hartog, 1996, 38. Hommes des réseaux, le messager et le héraut doivent à l'inverse se distinguer par leur rapidité, leur voix claire et leur parole fidèle pour assurer une diffusion exacte des informations à transmettre d'un lieu à l'autre. 
plement parcourir le vaste camp achéen constituent autant d'épreuves à surmonter en étant guidé, accompagné ou bien armé31. Sur mer, les risques paraissent encore plus grands. Jouet des dieux comme des tempêtes, le marin est, sans repère fixe, au mieux balloté d'une terre à l'autre, au pire englouti dans l'inconnu ${ }^{32}$. Ulysse résume à lui seul les malheurs de l'homme confronté à la distance. Nommé «odusseus» par son grand-père qui avait été par trop ulcéré lors de son voyage pour lui rendre visite, Ulysse souffre, des années durant, sans gloire et invisible aux siens, sur la mer inféconde et dans des mondes infra ou suprahumains ${ }^{33}$, connaissant ainsi une vie plus malheureuse encore que celles des exilés restés en contact avec la communauté humaine ${ }^{34}$.

Il faut dès lors se rapprocher. L'installation d'Ulysse dans le voisinage de Sparte garantit notamment à Ménélas le soutien matériel d'un ami, d'un hôte ou d'un voisin ${ }^{35}$, toujours indispensable dans une société qui repose sur l'entraide de ses membres ${ }^{36}$. La proximité spatiale permet également à leur relation amicale de se réactiver régulièrement. Le contact physique et immédiat reste en effet, dans la société homérique, un puissant vecteur d'accomplissement des rôles sociaux et des devoirs héroïques. S'il faut toucher son proche pour concrétiser et raffermir les liens familiaux ou affectifs ${ }^{37}$, il est aussi nécessaire de prendre le menton ou les genoux d'autrui pour obtenir son indulgence ou son hospitalité bienveillante ${ }^{38}$. Le contact est, par ailleurs, indispensable aux hommes comme aux dieux ${ }^{39}$ qui souhaitent développer l'ardeur de leurs protégés. Au combat, le chef parcourt ainsi les rangs de ses troupes pour stimuler, à l'oral et en personne, chacun de ses hommes ${ }^{40}$. Dans l'oikos, le maître doit encore voir régulièrement ses gens pour soutenir leur zèle ouvrier ${ }^{41}$.

Terreau de la construction identitaire, la proximité spatiale conditionne encore la naissance, la grandeur et la diffusion du kleos hérö̈que. La réalisation de l'exploit à son origine requiert tout d'abord la présence de la collectivité. Dans une société où le regard de l'autre façonne l'identitéf2, le héros doit, à l'image de Sarpédon, d'Achille ou d'Euchénor, quitter sa lointaine demeure pour côtoyer les siens, se distinguer parmi les foules ${ }^{43}$ et surtout se distinguer par des actions visibles de tous ${ }^{44}$. Malheur dès lors à ceux qui vivent loin des autres: ils n'auront, comme solde de leur iso-

31 Homère, Iliade, X, 65-66, 224-226; Odyssée, II, 20-24, III, 323-326, VI, 112-114, 297-308, VII, 14-17, 28-36, 139-145; XV, 307-316; XVI, 212-216.

32 Homère, Odyssée, II, 363-370; III, 317-322; IV, 481-484; V, 173-176; XII, 279-293; XIII, 418-419 et F. Hartog, 1982, 415 et 422 . Une vie idéale, proche de l'âge d'or, semble exclure toute traversée en mer. Tel est le cas dans l'utopie phéacienne homérique et pour les habitants de la cité juste hésiodique (Les Travaux et les Jours, 236).

33 Homère, Odyssée, I, 1-5, 49-50, 74-75, 231-240; II, 332-336; VII, 241-250; VIII, 408-411; IX, 29-36, 72-73, 259-261; X, 457-465; XI, 164-169; XIV, 130, 367-371; XXIII, 67-68; XIX, 399-412.

34 Sur leurs souffrances: Homère, Odyssée, IV, 743744; XV, 381-382; XVI, 380-382; XVIII, 165-171.

35 Sur ce point Homère, Iliade, II, 362-363; VI, 12-17; Odyssée, V, 488-490; VIII, 205-211.

36 Sur ce point, voir par exemple Lévy 1995, 184 et Larran 2011, 73-94.

37 Par exemple Homère, Iliade, V, 407-409; Odyssée, XVI, 14-20, 31-39, 190-191; XIX, 472-475 ; XXI,
221-225. À l'inverse, l'opprobre est promis à la femme qui, trop dure, se tient loin de son époux (Homère, Odyssée, XXIIII, 88-103, 166-173).

38 Par exemple Homère, Iliade, I, 498-502, VI, 45-62, VIII, 370-372, X, 454-456; Odyssée, VI, 141142; XXII, 310-312, 341-345.

39 Notamment Homère, Iliade, II, 450-454, IV, 514-516; Odyssée, XIII, 383-396.

40 Par exemple Homère, Iliade, IV, 223-250, 493497; Odyssée, XII, 204-206, 391-392.

41 Homère, Odyssée, XV, 376-379 et XVI, 320-321.

42 Sur ce point, consulter Frontisi-Ducroux 1995 avec Frontisi-Ducroux et Vernant 1997, 11-50 et 251285.

43 Les signes d'autorité et de noblesse sont toujours à exhiber en public (par exemple Homère, Iliade, II, 474483, VIII, 220-221; Odyssée, VI, 25-30, 57-65, 101 109, VII, 69-77, VIII, 166-175, XVI, 244-246).

44 Homère, Iliade, V, 472-484, IX, 410-416 et XIII, 663-672 avec Larran 2011, 73-94 et Collobert 2011, 136. 
lement, que le droit à l'oubli ${ }^{45}$. Une fois l'exploit réalisé sous le regard de la communauté assemblée, il faut encore assurer la diffusion spatiale de sa renommée. Chanté par un aède itinérant ou bien colporté par l'étranger informé par son hôte, le kleos vit du contact immédiat et personnel établi avec les hommes de la mobilitét ${ }^{46}$. Sa grandeur dépend également enfin de l'entourage du héros. Récompense individuelle d'une action mise au service de la collectivité, le kleos dépend toujours, comme la timè et l'arétè, du rapport à autrui ${ }^{47}$. Alors que la timè d'Arété et des Phéaciens sort grandie du contact avec leur hôte Ulysse ${ }^{48}$, Pénélope reconnait encore : «Ma valeur (arétè), ma beauté, mes grands airs (...), les dieux m’ont tout ravi, lorsque, vers Ilion, les Achéens partirent, emmenant avec eux Ulysse, mon époux! Ah! S'il me revenait pour veiller sur ma vie, que mon renom (kleos) serait et plus grand et plus beau! ${ }^{49}$.

Engagé, comme les autres héros, dans une spatialité morale mue par des relations d'honneur identitaire, Ménélas cherche, avec son projet, à répondre à l'éclatement géographique d'une communauté achéenne durement éprouvée à son retour de Troie. Victimes d'une sanction divine infligée pour punir leurs impiétés ${ }^{50}$, les Achéens sont la proie d'une dispersion susceptible de conduire à l'éclatement des histoires individuelles, d'entraver la récitation poétique d'exploits héroïques trop lointains pour être connus ${ }^{51}$ et de menacer ainsi la transmission d'une mémoire collective indispensable à l'édification des générations suivantes ${ }^{52}$. À la différence des dieux qui, aussi loin vivent-ils les uns des autres, ne peuvent s'oublier $^{53}$, les Achéens sont bien menacés par une distance qui les coupe les uns des autres, dissout leurs relations identitaires et contrarie leur survie mémorielle. Dans un tel contexte, Ménélas a bien tout à gagner du transfert d'Ulysse dans le voisinage de Sparte: un soutien matériel, un contact stimulant son arétè et nourrissant sa time $e^{54}$ mais aussi une histoire commune tissée au fil de leur klea et chantée au cœur du monde achéen. Idéal, l'espace héroïque imaginé par Ménélas ne pouvait effectivement se concevoir aux marges du monde... Il n'aurait sans doute pas alors suscité la jalousie des dieux!

\section{Quitter Ithaque pour Argos ou les vertus relationNelles de L'espace hÉroÏQue}

D'Ithaque à Argos. De la périphérie au centre, et non l'inverse. Ménélas n'entend pas s'établir dans un pays placé aux limites occidentales du monde achéen, mais au contraire faire venir Ulysse

45 Tel est le risque encouru par Philoctète banni sur une île par les Achéens (Homère, Iliade, II, 721-726) comme par Télémaque et Ulysse lors de leurs voyages (Homère, Odyssée, IV, 707-611, XIV, 136-147, XXIV, 214-218 avec Sebillotte Cuchet 2006, 26-44.

46 Homère, Odyssée, VIII, 100-103, 241-253, 496498; XVI, 381-385, 415-421; XIX, 332-334. La diffusion spatiale du kleos est également assurée par l'érection de tertre, la conservation du butin et la distribution de cadeaux d'hospitalité qui assurent, d'un lieu à l'autre, sa remémoration (Larran 2011, 73-94).

47 Sur ce point Lévy 1995.

48 Homère, Odyssée, XI, 336-341. À l'inverse, Achille déshonoré (atimêton) par Agamemnon vit à l'écart des Achéens (par exemple Homère, Iliade, IX, 646-648).

49 Homère, Odyssée, XVIII, 251-253 (= XIX, 124126).
50 Homère, Odyssée, III, 130-168.

51 À la différence des dieux et des Muses qui, partout présents, savent tout, les hommes incapables de dominer entièrement l'espace sont toujours la proie de l'ignorance (par exemple Homère, Iliade, II, 484487).

52 Sur ce point Bouvier 2002.

53 Homère, Odyssée, V, 76-80.

54 Riedinger 1976, 247-248 précise que l'amitié (philotès) est étroitement liée à l'honneur (timè). Pour lui, les liens d'amitié sont des liens d'honneur réciproque. À l'inverse, l'étranger et l'errant misérable, exclus de toute relation sociale et en rupture topographique avec le groupe, sont par là-même exclus de toute timè, comme le montre Achille qui s’isole, déshonoré, après avoir rompu avec Agamemnon (Homère, Iliade, IX, 648, XVI, 59, XXIV, 533). 
en son cœur. Le transfert proposé par l'Atride fait le lien entre deux espaces aux valeurs opposées $^{55}$. Terre rocheuse, périphérie sombre placée aux franges du monde connu ${ }^{56}$, Ithaque est bien à lire comme le miroir au négatif d'Argos, mamelle de la terre représentée comme le centre riche et rayonnant du monde hérö̈que ${ }^{57}$.

Quitter son pays à chèvres pour s'implanter dans les riches terres à blé et les vastes plaines à chevaux d'Argos ${ }^{58}$ relève sans doute, pour Ulysse, d'un mouvement positif dont la portée s'apprécie à la lumière des autres voyages traversant le monde de l'Odyssée. Les trajets conduisant de son centre à ses périphéries occidentales se distinguent régulièrement par leur caractère négatif. Ce sont souvent des trajets de mort: si les âmes des prétendants sont accompagnées par Hermès vers le lointain Hadès ${ }^{59}$, les longues errances d'Ulysse, à partir du Cap Malée jusqu'à l'île de Calypso, risquent de le faire disparaitre dans l'inconnu. Dans une perspective identique, c'est vers la lointaine Sicile du terrible roi Échétos que l'on promet d'envoyer les indésirables d'Ithaque ${ }^{60}$. À l'inverse, les déplacements s'effectuant des périphéries vers le centre du monde achéen riment souvent avec le retour à la vie et à la lumière. Si les nostoi des héros ont comme destination Argos, pays de vie et de lumière d'après P. Sauzeau ${ }^{61}$, la Télémachie conduit le fils d'Ulysse d'une petite île périphérique plongée dans l'anarchie politique vers le cœur souverain du monde hérö̈que, où il apprendra les bonnes mœurs héroïques autant qu'il écoutera le kleos de son père, nécessaire à sa construction identitaire $^{62}$. Mise en perspective avec les errances d'Ulysse, la proposition de Ménélas consistant à l'implanter dans le pays lumineux d'Argos constitue encore une étape symbolique de son retour au monde héroïque. Régulièrement invité à s'établir auprès de ses hôtes, Ulysse tourne d'abord le dos à l'immortalité offerte par Calypso qui voudrait bien le «cacher» pour toujours dans son île comme il refuse ensuite la proposition d'Alkinoos de devenir son gendre en Phéacie, pays d'ombre et de lumière à mi-chemin entre le monde mythique et le monde humain ${ }^{63}$.

Plus que la localisation réelle de la ville offerte à Ulysse, c'est sans doute la valeur des relations établies entre les espaces qui fait ainsi sens dans le projet de l'Atride. La dimension morale et symbolique du transfert de l'oikos d'Ulysse l'emporte assurément sur la réalité géographique d'une œuvre épique qui façonne l'espace au ciment de l'identité de ses occupants ${ }^{64}$. Loin de la géographie déterministe accordant le primat aux éléments naturels, l'Iliade et l'Odyssée mettent le paysage au diapason de l'identité humaine. La plaine de Troie est ainsi vidée de ses traits physiques pour vivre au rythme de la guerre et servir de théâtre naturel symbolique au déchaînement des fureurs humaines. Les manoirs, les cités comme les pays sont, de la même façon, reconstruits pour exprimer la valeur de leurs habitants. Les luxueux palais d'Alkinoos et de Ménélas disent autant le prestige de leurs propriétaires que les plaines grasses la richesse de leurs occupants et le paysage rocailleux l'endurance des peuples qui $y$ vivent ${ }^{65}$.

55 Homère, Odyssée, IV, 600-608 et XIII, 242 sq avec Sauzeau 2004, 134 et 2005, 33.

${ }^{56}$ Homère, Odyssée, IX, 22-26 avec Ballabriga 1998, 40-42 et Sauzeau 2005, 37.

57 Homère, Iliade, IX, 141, 283; Odyssée, I, 334 avec Ballabriga 1986, 64 et Sauzeau 2005, 27-28, 33-34, 51 et 223 .

58 Par exemple Homère, Iliade, XV, 372; Odyssée, IV, 101, 600-608.

59 Homère, Odyssée, XXIV, 10-14. Voir aussi Homère, Iliade, III, 3-7 et Odyssée, XX, 61-81.
${ }^{60}$ Homère, Odyssée, XVII, 248 sq; XVIII, 85, 116; XX, 376-383 ; XXI, 307-308.

61 Sauzeau 2005, 30.

${ }^{62}$ Homère, Odyssée, I, 93-95 avec Larran 2011, 141-144.

${ }^{63}$ Homère, Odyssée, V, 205-213, VII, 316-316 avec Vidal-Naquet 1970, 1278-1297 et Sauzeau 2005, 37.

64 Voir ici Bouvier 1986; Rougier-Blanc 2002, $101-$ 116; Sebillotte Cuchet 2006, 56-57.

65 Voir ici les analyses de Sebillotte Cuchet 2006, 50-57. 
Pourquoi dès lors dénier à Argos son pouvoir d'expression métaphorique? Si l'espace dans l'épopée homérique est bien reconfiguré en fonction des caractères de ses occupants, l'Argos imaginée par Ménélas exprime elle aussi, par ses structures et ses relations spatiales, l'idéalité héroïque d'un projet à même de susciter la jalousie des dieux. Centre luxueux du monde organisé en fonction des activités aristocratiques telles que les courses de chevaux et les récitations poétiques $^{66}$, Argos est encore à considérer comme un espace parfait en raison de sa capacité à mettre en contact les lieux et autoriser ainsi une continuité spatiale nécessaire au fonctionnement de la société homérique. Nœud relationnel à l'échelle du monde achéen, l'espace de Ménélas pourrait attirer Ulysse et les siens comme il fait venir régulièrement à lui les héros des autres parties du monde achéen. Parmi les visiteurs, on compte Idoménée, Télémaque et Pisistrate, très probablement Agamemnon et peut-être aussi Nestor avec qui Ménélas continue d'entretenir de solides relations d'amitié ${ }^{67}$. Au nombre des espaces en contact avec le manoir de l'Atride figurent la Phthie de Néoptolème mais aussi Pylos des Sables, Argos et l'Hellade au sein desquels Ménélas voyage en hôte toujours bien accueilli68. Si Télémaque et Pisistrate franchissent aisément l'espace pourtant montagneux séparant Pylos de Sparte ${ }^{69}$, Ménélas assure qu'il trouvera toujours portes ouvertes à Argos et en Hellade, là-même où volent son kleos comme celui d'Ulysse et $\mathrm{d}^{\prime}$ Oreste $\mathrm{e}^{70}$.

La discontinuité spatiale ne joue pas davantage à l'échelle locale. Lors des festivités organisées pour célébrer le double mariage de sa fille Hermione avec Néoptolème et de son fils Mégapenthès avec la fille d'Alector, Ménélas accueille en son manoir ses familiers comme ses voisins ${ }^{71}$. La remarque est d'importance, car le fonctionnement d'Argos tel qu'il est imaginé par Ménélas semble intimement lié à celui du banquet. Moteur des liens d'hospitalité établis avec les autres héros achéens, le banquet pourrait encore rythmer les relations de Ménélas avec Ulysse installé à Argos. À l'origine de leur «accord et de leurs joies» (terpomenô), les festivités projetées par l'Atride consacreront autant leur amitié ${ }^{72}$ qu'elles leur permettront de vivre à une distance idéale l'un de l'autre. S'il faut accueillir son hôte en son manoir, il ne faut pas jamais cependant, dans l'Odyssée, rester avec lui dans une situation de coprésence totale. Espace d'intégration provisoire, la salle des festivités est située, dans le manoir, entre la chambre privée où se retire le maitre et l'entrée où dort le convive ${ }^{73}$. Alors que le banquet joue le rôle de microcosme de la société homérique en utilisant les places d'honneur pour refléter ses hiérarchies et ses rapports sociaux, politiques et militaires ${ }^{74}$, il sert encore d'étalon pour configurer les structures spatiales d'Argos imaginée au chant IV de l'Odyssée. Ménélas et Ulysse devront y vivre comme on vit au banquet : des relations constantes et concrétisées certes dans le proche immédiat de la salle des festivités mais qui imposent à chacun de rentrer, le soir, dans son propre manoir.

Bâti sur le patron du banquet, espace référent pour penser et organiser la société homérique, l'Argos de Ménélas désigne moins une réalité géographique qu'il ne sert la stratégie narrative du

66 Consulter Sauzeau 2004. Comme l'aède, Ménélas charme Télémaque grâce à ses récits (Homère, Odyssée, IV, 156-160, 594-598). Sur les récitations poétiques chez Ménélas, voir aussi Homère, Odyssée, IV, 1-19.

67 Homère, Iliade, III, 232-233, Odyssée, III, 277-282,

IV, 1 sq, 514 (avec Malkin 1999, 48) et XV, 151-153.

68 Homère, Odyssée, IV, 1-14, XV, 75-85.

69 Homère, Odyssée, III, 323-326, $491-497$ et XV, 193 avec Sauzeau 1998.

70 Homère, Odyssée, I, 298, 344 et IV, 724-727.
71 Homère, Odyssée, IV, 1-19.

72 Sur le banquet comme moment de consécration d'une amitié: Homère, Odyssée, XXI, 34-36.

73 Sur ces pratiques: Homère, Iliade, I, 601-611; Odyssée, I, 421-424, II, 394-398, III, 397-403, IV, 301-305, 343-347, XX, 1-4 avec Rougier-Blanc 2007, 60-61.

74 Consulter par exemple Carlier 1984, 154-157; Scheid-Tissinier 1988, 300-301; Rougier-Blanc 2007, 58-59. 
poète $^{75}$. L'épopée semble bien utiliser Argos comme un concept spatial utile pour déchiffrer le monde, comparer les situations et classer les sociétés sur l'échelle des valeurs humaines ou héroïques. Parmi les anti-Argos, on compte bien sûr les espaces infrahumains visités par Ulysse lors de ses errances méditerranéennes. Éclaté et fermé au monde extérieur, le monde des Cyclopes fait figure de repoussoir absolu: "Nous arrivons au pays des Yeux Ronds, brutes sans foi ni lois (...). Chez eux, pas d'assemblée qui juge ou délibère ; mais au haut des grands monts, au creux de sa caverne, chacun sans s'occuper d'autrui, dicte sa loi à ses enfants et femmes» ${ }^{76}$. Si les espaces des Lestrygons et d'Éole sont, quant à eux, moins fragmentés, ils restent encore, à l'inverse d'Argos, fermés au monde ${ }^{77}$.

La situation anarchique d'Ithaque pourrait encore prendre le contre-pied de l'idéal spatial argien. La discontinuité spatiale sévit à toutes les échelles. Ouvert au monde extérieur avant la guerre de Troie, le manoir reçoit la visite d'Autolycos, de Mentès, d'Agamemnon et de Ménélas et, de façon plus générale, d'amis venus de tous les coins du monde ${ }^{78}$. Ulysse entreprend quant à lui des voyages dans le Péloponnèse, notamment en Messénie où il lie amitié avec Orsiloque ${ }^{79}$. En l'absence d'Ulysse, les contacts avec l'extérieur se font rares et incertains. Si le kleos d'Ulysse n'est plus chanté à Ithaque, les nouvelles de son retour sont distillées encore au hasard des venues de quelques rouleurs de mer qui n’hésitent à mentir ni à Eumée ni à Pénélope pour obtenir leurs bonnes grâces ${ }^{80}$. Les relations familiales semblent également distendues si l'on en croit les regrets de Pénélope de ne plus assez recevoir les visites de sa sœur ${ }^{81}$. Le déclin du manoir d'Ulysse s'apprécie également à plus grande échelle. La salle des festivités est occupée, quotidiennement, par des prétendants impies qui, non contents de manger les biens de son propriétaire, contraignent l'aède Phémios à chanter selon leur bon vouloir et interdisent à Télémaque de gérer, comme il l'entend, l'espace de son manoir ${ }^{82}$. Conséquence des dysfonctionnements du manoir, l'oikos est la proie de la fragmentation. Ses espaces sont mal ou peu interconnectés. Alors que Télémaque rend rarement visite à ses bergers, Laërte vit retiré aux champs sans descendre en ville tout comme Eumée qui ne vient au manoir qu'à contrecœur pour apporter les victuailles nécessaires aux banquets de débauche $^{83}$. Probable transcription spatiale de l'indifférence des habitants d'Ithaque à l'égard des abus des prétendants, la maison d'Ulysse semble encore placée en retrait d'une ville dans laquelle Télémaque ne se rend que bien accompagné tant le chemin qui y conduit semble dangereux ${ }^{84}$. Dans de telles conditions, la reconquête de la royauté par Ulysse passera, pour être pleine et entière, par le contrôle et la mise en interrelation des espaces de son oikos. La salle de banquet est, depuis le seuil, à reprendre par le combat comme par le contrôle des déplacements des prétendants ${ }^{85}$. Les espaces de l'île sont ensuite à relier les uns aux autres : une fois de retour, Ulysse circule, en maître, entre la maison d'Eumée, le manoir, la ville et le domaine de Laërte ${ }^{86}$. Les structures spatiales de l'oikos sont enfin remodelées pour gratifier les fidèles soutiens d'Ulysse et fondre ainsi, dans le moule ar-

75 Sur ce point Wathelet 1992, 106 et Sauzeau 2005, 17, 29 et 32 .

76 Homère, Odyssée, IX, 105-115. Voir encore Homère, Odyssée, IX, 187-189 avec Vlachos 1974, 48-49.

77 Voir ici les analyses de Vlachos 1974, 51-52.

78 Homère, Odyssée, I, 206-212, 253-265, XIX, 399-412; XXIV, 114-119.

79 Homère, Odyssée, XXI, 13-41.

80 Homère, Odyssée, XIV, 115-127, 156-157, $372-$ 389 et XVII, 508-512.

81 Homère, Odyssée, IV, 810-811.
82 Homère, Odyssée, I, 125-135, 154, 244-251, 368-380, II, 138-145, XX, 169-171, XXI, 331-333 et E. Cantarella, 2003, 105-119.

83 Homère, Odyssée, I, 189-193, IV, 735-741, XI, 187-191, XIV, 372-389, XV, 352-364, XVI, 23-29, XXIV, 205-212.

84 Homère, Odyssée, II, 20-24 et Rougier-Blanc 2002, 104.

85 Homère, Odyssée, XVII, 336-349, 412-414, XX, 257-269, XXI, 349-353.

86 Homère, Odyssée, XVII, 157-161. 
gien, l'espace héroïque reconquis. De façon caractéristique, Ulysse propose à ses amis Eumée et Philoetios un projet de nature assez comparable à celui de Ménélas: «Si quelque jour un dieu jette sous ma vengeance les nobles prétendants, je vous marie tous deux, je vous donne des biens, je vous bâtis une maison près de la mienne et pour moi, désormais vous êtes les amis, les frères de mon fils» ${ }^{87}$.

Reconfiguré selon les canons de la spatialité héroïque, l'oikos reconquis par Ulysse repose notamment sur la mise en interrelation de ses composantes. Il se rapproche en cela des espaces qui ont pu, eux-mêmes, inspirer l'Argos de Ménélas. Deux voies de comparaison s'ouvrent ici à l'analyse.

Le campement d'Achille compte assurément parmi les espaces hérö̈ques propices à l'imitation pour l'Atride. Précisément appelées Argos à la fin de l'Iliade ${ }^{88}$, les baraques des Myrmidons sont le théâtre d'une vie hérö̈que dont le caractère idéal semble renforcé par la proximité constante établie entre Achille et Patrocle. Comme à Argos, le campement d'Achille en colère vit au rythme de ses récitations poétiques et des jeux athlétiques organisés au milieu des chevaux ${ }^{89}$. Dans le cercle des innombrables nefs des Myrmidons, Patrocle n'est jamais loin d'Achille: il dort à l'autre bout de sa baraque comme il écoute, seul face à lui, ses chants héroïques. Même la mort ne peut les séparer puisque les Achéens placent ses os blanchis dans l'urne funéraire d'Achille ${ }^{90}$. Ménélas cherche-t-il à reproduire l'espace achilléen quand il propose à Ulysse de s'installer à Argos? L'hypothèse n'est pas à exclure, tant les avantages à tirer de cette stratégie sont nombreux pour l'Atride. Prendre modèle sur Achille et Patrocle, c'est placer sa relation avec le seul héros de l'Odyssée ${ }^{91}$ dans les traces d'une amitié exceptionnelle92. La proposition pourrait même avoir de quoi séduire Ulysse qui hésite, au début de son nostos, entre le parti de Ménélas et celui d'Agamemnon ${ }^{93}$. S'inspirer de la spatialité achilléenne, c'est encore effectivement permettre à Ménélas de soutenir le conflit qui l'oppose à Agamemnon au lendemain de la guerre de Troie. Après la violente colère qui déchire la fratrie des Atrides et scinde la flotte achéenne lors de son retour ${ }^{94}$, Ménélas fait montre d'une étonnante passivité à l'annonce de la mort d'Agamemnon ${ }^{95}$. Partageant peut-être les sentiments d'Achille selon lequel l'amitié est supérieure à tout autre intérêt ${ }^{96}$, Ménélas entend probablement rejeter la politique de son frère qui a contribué, par excès d'autoritarisme, au morcellement du camp achéen. Alors que leur dispute se solde par une discontinuité spatiale qui isole le Péléide à l'extrémité du camp ${ }^{97}$, Agamemnon propose encore à Achille, en guise de réparation, de devenir le roi lointain de sept villes probablement lacédémoniennes ${ }^{98}$. En suggérant à Ulysse de $s^{\prime}$ implanter auprès de Sparte, Ménélas fait le choix contraire d'une continuité spatiale entre deux amis de marque, com-

87 Homère, Odyssée, XXI, 213-216 avec Odyssée, XV, 301-306, 341-345 et Scheid-Tissinier 1988, 272-273.

${ }^{88}$ Homère, Iliade, XXIV, 437 avec Sauzeau 2005, 37-39.

89 Homère, Iliade, II, 771-779, IX, 189-191.

90 Homère, Iliade, IX, 185-191, 663-668; XVI, 67-69; XXIII, 243 sq avec Odyssée, XXIV, 71-86.

${ }^{91}$ Carlier 1984, 208. Pendant la guerre de Troie, Ulysse agit en compagnon dévoué à Ménélas pendant leur ambassade à Troie, lors d'une embuscade comme dans le cheval de Troie (Homère, Iliade, III, 202-214, XI, 138-142; Odyssée, IV, 105-112, 151-154, 266-285, 328-330, VIII, 516-520, XIV, 468-477).

${ }^{92}$ L'amitié d'Achille pour Patrocle est tellement forte que le Péléide n'hésite pas à considérer son com- pagnon comme son «autre moi-même» (Homère, Iliade, XVIII, 82, 121) avec Carlier 1984, 182.

${ }^{93}$ Homère, Odyssée, III, 162-164.

94 Homère, Odyssée, III, 130-168.

95 Homère, Odyssée, III, 301-318, IV, 90-101, 538541, 581-586 avec Vlachos 1974, 251-252.

${ }^{96}$ Homère, Iliade, XVI, 97-100. Alkinoos rappelle encore que "avoir un ami toujours plein de sagesse, c'est avoir mieux qu'un frère!» (Homère, Odyssée, VIII, 585586).

97 Sur la position des baraquements d'Achille dans le camp athénien: Homère, Iliade, VIII, 224-225, XI, 5-9.

98 Homère, Iliade, IX, 149-156 avec Carlier 1984, 179. 
parable à celle mise en œuvre dans les baraquements du grand héros de l'Iliade ${ }^{99}$. Dans le contexte de la désunion et de la dispersion des Achéens survenues au lendemain de la guerre de Troie, il était sans doute préférable pour Ménélas de prendre modèle sur la spatialité d'Achille, un héros au centre de tous les regards à la fin de l'Iliade et volontiers considéré comme le chef suprême des Achéens dans l'Odyssée ${ }^{100}$, plutôt que de reproduire celle de son adversaire Agamemnon qui a bien failli, par ses choix malheureux, mettre en péril l'expédition achéenne.

La concordance entre les structures spatiales de l'Argos de Ménélas et celles du campement d'Achille n'est cependant pas parfaite. Si Achille s'isole souvent, sur le rivage, dans l'orgueil de sa colère et de son malheur, Patrocle est, en Phthie, directement intégré dans l'oikos de son ami et vit, dans le camp achéen, dans son baraquement ${ }^{101}$. La mise en parallèle suggérée, dans l'Odyssée, entre Lacédémone, Schérie et Ithaque ${ }^{102}$ pourrait encore laisser entendre que l'Argos de Ménélas prend modèle sur la Phéacie. Bien que jamais désigné par le terme Argos qui s’applique sans doute aux seules sociétés humaines, le monde d'Alkinoos montre effectivement d'étroites similarités avec l'espace à l'étude. Il répond comme lui aux mêmes logiques organisationnelles. Si le transfert d'Ulysse à Argos pourrait être considéré comme la transfiguration spatiale de l'intégration du fils de Laërte au monde héroïque, la mise à distance du monde cyclopéen par les Phéaciens qui choisissent d'établir Schérie sur la côte est considérée, par A. Ballabriga, comme la transposition spatiale de l'effacement de leur gigantisme guerrier ${ }^{103}$. Plus sûrement encore, le manoir de Ménélas se distingue par un éclat et un luxe comparables à celui d'Alkinoos ${ }^{104}$. Les banquets, les concours athlétiques comme les récitations poétiques organisés en Phéacie ${ }^{105}$ répondent tout autant aux activités aristocratiques d'Argos. Traduction spatiale de l'harmonie sociale, les espaces phéaciens disposés selon une contiguïté symbolique sont aisément et régulièrement mis en contact. On se déplace ainsi sans difficulté entre le manoir d'Alkinoos, sa fontaine et son verger, les agorai et le port nécessaire aux voyages des Phéaciens dans le monde entier ${ }^{106}$. Comme dans l'Argos imaginée par Ménélas, les nobles phéaciens habitent enfin suffisamment près du manoir d'Alkinoos pour y banqueter quotidiennement et regagner leurs logis après les festivités ${ }^{107}$. La fluidité des déplacements dans un espace qui vit au rythme des banquets semble ainsi être au diapason d'une utopie, fondée sur la concorde sociale et l'entente politique entre des aristocrates régulièrement mis en contact ${ }^{108}$. Le parallèle entre l'espace à l'étude et le monde phéacien pourrait même se poursuivre jusque dans leur échec. Si l'Argos de Ménélas ne voit jamais le jour, le monde phéacien, déjà sans voisins, se referme définitivement sur lui-même, puni par Poséidon pour avoir permis le retour d'Ulysse à Ithaque ${ }^{109}$. Espaces idéaux, ils avaient sans doute moins vo-

99 Sur la préférence accordée, dans l'Iliade, à Achille: Daude 2007, 39-62.

100 Homère, Odyssée, III, 103-110, XI, 484-486, XXIV, 15-22

101 Par exemple Homère, Iliade, I, 345-350, IX, 426, XXIII, 83-90.

102 Sur l'importance de la mise en parallèle Ithaque - Schérie - Sparte dans l'Odyssée: Lowenstam 1993, 179-184.

103 Ballabriga 1998, 194.

104 Homère, Odyssée, IV, 45-47, 71-74 et VII, 81102.

105 Homère, Odyssée, VIII, 40-45, 147-148, 241 253.
106 Homère, Odyssée, VI, 258-308, VII, 43-46, $112-$ 132, VIII, 4-18, 56-61 avec Rougier-Blanc 2002, 103104.

107 Homère, Odyssée, VI, 255-257, VII, 48-52, 95-98, 134-138, 186-191, 228-229, 255-257, XIII, 8-9, 16-17.

108 Sur l'utopie phéacienne, se référer notamment à Homère, Odyssée, IX, 2-11 avec Carlier 1984, 204-205. La fréquence des contacts établis entre Alkinoos et les douze autres basileis, au niveau desquels il assure se placer, participe directement de l'idéal politique phéacien (Homère, Odyssée, VIII, 390-391 avec Carlier 1984, 213-214 et Ruzé 1989, 218-219).

109 Homère, Odyssée, VI, 179, XIII, 159-183. 
cation à fonctionner pleinement dans l'épopée homérique qu'à donner à penser dans un monde grec confronté à de profondes mutations spatiales.

\section{Au PLUS PRÈs DU LOINTAIN ULYSSE OU LA SYNTHÈSE IDÉALE DES ÉCHELLES}

Du vaste au petit, de l'ouverture au repli et encore des relations interrégionales aux contacts locaux... La période comprise entre le XIII ${ }^{\mathrm{e}}$ et le $\mathrm{VIII}^{\mathrm{e}}$ siècles conduit-elle aussi simplement le monde mycénien à l'éclatement en une multitude de petites entités autonomes qui s'épanouiront ensuite en tant que cité? Son histoire n'est certainement pas de celles à se laisser enfermer dans le cours unique et linéaire d'un progrès fléché menant de l'ombre du déclin à la lumière de la renaissance. L'hypothèse d'un monde post-palatial, immobile et replié sur lui-même, a déjà eu à subir l'assaut des analyses de N. Purcell comme de C. Broodbank qui voient dans les Âges obscurs une période de migrations, d'échanges intenses et de contacts avec les Barbares ${ }^{110}$. L'interprétation traditionnelle figeant les migrants de l'époque post-palatiale dans le rôle de réfugiés aux abois a encore fait les frais de la démonstration d'A. Schnapp-Gourbeillon ${ }^{111}$. L'histoire des XIII ${ }^{\mathrm{e}}$-VIII ${ }^{\mathrm{e}}$ siècles se distingue aujourd'hui par une réelle complexité alimentée par les initiatives d'aristocrates créatifs, euxmêmes liés par de nouvelles formes de compagnonnage. Pris dans des mouvements centripètes autant que centrifuges, le monde grec donne alors naissance à de petites communautés locales mais aussi à des synœecismes, à des fédérations politiques et enfin aux premières cités. Libérées des anciennes certitudes d'un monde mycénien mis en système pour servir son wanax, les Grecs des Âges dits obscurs comme du haut archaïsme laissent libre cours à une nouvelle Weltanschauung focalisée sur la question du morcellement et de l'autonomie locale ${ }^{112}$. Quelle est l'échelle idéale de gouvernement? Quelle dimension la communauté doit-elle atteindre? Quelle distance et quel type de contact est-il raisonnable d'instaurer entre ses membres pour lui donner sens et réalité? Fille d'une période de haute créativité politique mais aussi de profondes mutations spatiales, l'Odyssée résonne des questionnements contemporains sur la bonne distance et entend probablement, dans le dédale des initiatives, les orienter grâce au projet de Ménélas.

L'Atride et son compagnon Ulysse se révèlent effectivement d'utiles adjuvants pour penser les liens communautaires. Engagés par un code hérö̈que qui, plastique, fixe des rôles spécifiques à chacun, ils doivent tous deux gagner un noble kleos pour être chantés par-delà les siècles et contribuer ainsi, par leurs exemples, à l'édification des générations futures ${ }^{113}$. À Ménélas non pas l'épreuve du combat mais celle, imposée par Zeus ${ }^{114}$, de la défense de l'hospitalité et des liens amicaux $^{115}$. Victime de Pâris qui a violé, lors de son passage à Sparte, les devoirs de l'hôte en s'emparant d'Hélène ${ }^{116}$, l'Atride reconnaît ainsi avant de l'affronter en duel: «Sire Zeus! Donne-moi de punir celui qui m’a, le premier fait tort, le divin Alexandre, et dompte-le sous mon bras. Ainsi chacun désormais, jusque chez les hommes à naitre, redoutera de faire tort à l'hôte qui lui a montré amitié» ${ }^{17}$. Sa vocation se donne encore à lire, selon P. Rousseau, dans le fonctionnement de la

110 Purcell 1992, 43-78 et Broodbank 2013.

111 Schnapp-Gourbeillon 2002, 108-110, 127-128.

112 Consulter par exemple ici Vlachos 1974, 161-

162 et Schnapp-Gourbeillon 2002, 316-317.

113 Voir ici Collobert 2011, notamment 131-137.

114 Homère, Iliade, VI, 357-358.

115 Sur ce point Rousseau 1990, 325-354 et 1992, $57-79$.
116 Pour Rousseau 1990, 349, Ménélas est victime de la violation répétée des règles, comme le montrent l'attentat de Pandare à la fin de son duel contre Pâris mais encore la manœuvre déloyale d'Antiloque lors des jeux funèbres (Homère, Iliade, IV, 155-159...).

117 Homère, Iliade, III, 351-354. 
dyarchie au pouvoir dans l'Iliade. Associé à son frère dans le commandement de l'armée achéenne, Ménélas agit en souverain conciliant et amical pour mieux laisser à son frère la figure de la majesté redoutable. Bienveillant à l'égard des ennemis troyens et soucieux du sort des Achéens ${ }^{118}$, Ménélas cherche à préserver l'amitié, la cohésion et la paix de la communauté par le recours au droit et à la négociation ${ }^{119}$. Dans cette perspective, Ménélas a beaucoup à partager avec Ulysse, un héros également associé à la défense de la cohésion communautaire. Installé au centre des nefs, tout près de l'agora, des autels et de la themis, Ulysse œuvre, au chant II de l'Iliade, pour le rétablissement de l'ordre dans les troupes achéennes ${ }^{120}$. Après avoir été relégué aux marges de la civilisation dans l'Odyssée, le fils de Laërte rentre à Ithaque, met un terme à l'anarchie provoquée par les prétendants et se réjouit de la concorde civile, ainsi souhaitée par Zeus: «Puisque les prétendants ont été châtiés par le divin Ulysse, pourquoi ne pas sceller de fidèles serments? Il garderait le sceptre; nous, aux frères et fils de ceux qui sont tombés, nous verserions l'oubli, et l'ancienne amitié les unissant entre eux, on reverrait fleurir la richesse et la paix $»^{121}$.

Ainsi éclairé, le vœu de Ménélas d'implanter Ulysse à Argos pourrait servir les desseins d'une épopée qui met en tension, selon G. C. Vlachos, les nouvelles valeurs d'un monde archaïque tourné vers la patrie particulière (le village, la région) et celles d'un hellénisme ancien porté par l'idée d'une unité plus large ${ }^{122}$. Contre l'autoritarisme monarchique d'Agamemnon qui disloque dangereusement la vaste association des Achéens, en phase avec leur dispersion géographique survenue après la Guerre de Troie ${ }^{123}$, l'Argos de Ménélas pourrait faire écho à nombre d'entreprises du $\mathrm{IX}^{\mathrm{e}}$ ou du VIII ${ }^{\mathrm{e}}$ siècles qui entendent précisément tirer profit des vertus de l'échelle locale ou régionale. Le projet de l'Atride peut-il ainsi servir de justification, voire de patron, aux nouvelles confédérations politiques? Comme l'Argos imaginée par Ménélas, le fonctionnement des royautés fédérales d'Achaïe, d'Arcadie, d'Ionie et de Thessalie repose sur l'association de villes voisines ${ }^{124}$. Au fondement de l'espace héroïque idéal dans l'Odyssée, la mise en contact régulière de deux villes pourrait constituer un argument de poids pour qui souhaite compenser les effets de la dispersion géographique par le changement d'échelle de gouvernement. Aussi suggestive soit-elle, l'hypothèse ici posée reste cependant risquée. L'Argos de Ménélas n'envisage effectivement ni l'existence de liens politiques entre Sparte et la ville offerte à Ulysse, ni l'instauration de magistratures fédérales pour gérer leur alliance. Ménélas propose seulement à Ulysse d'être son voisin.

Faut-il dès lors se tourner vers les synœcismes qui, en associant plusieurs oikoi, semble davantage reprendre le projet de Ménélas? Regroupement fréquent dans le monde grec dès le IX ${ }^{e}$ siècle, le synoecisme paraît, à Sparte, s’inspirer directement du projet de Ménélas. Si les Lacédémoniens ont pu installer leurs amis dans des cités périèques ${ }^{125}$, l'association entre leur ville et le village périphérique d'Amyclées ${ }^{126}$ s'offre volontiers comme le pendant historique des relations de proximité envisagées par Ménélas au chant IV de l'Odyssée. Déjà suggérée par A. Fanta, l'hypothèse pourrait encore se nourrir ici, a contrario, de l'absence de liens strictement politiques entre Ulysse et Ménélas. Focalisé sur les seules relations amicales et l'association de leurs oikoi particuliers, le projet de

118 Homère, Iliade, III, 97-102, VI, 45-62, X, 25-28; Odyssée, IV, 90-101

119 Par exemple Homère, Iliade, III, 67-73 avec Karavites 1992,54 .

120 Voir ici Homère, Iliade, VIII, 222-226, XI, $807-$ 808 avec Bouvier 2002, 275.

121 Homère, Odyssée, XXIV, 482-486 avec 545-547.

122 Vlachos 1974, 252-255.
123 Homère, Odyssée, III, 130-168.

124 Sur les royautés fédérales du haut archaïsme Carlier 1984, 509, 407-408, 417, 454-455.

125 Fanta 1882, 52 sq avec Pausanias, IV, 14, 3.

126 Sur le synœcisme grec en général et spartiate en particulier: Bertrand 1997, 10-11 et 20-23; Christien et Ruzé 2007, 17, 20 et 23 avec Éphore, FGrH 70 F 117 (= Strabon, VIII, 5, 4). 
l'Atride porte peut-être en lui les marques de la dépersonnalisation des liens politiques à l'œuvre dans la cité naissante et qui sont déjà visibles, dans l'Odyssée, avec l'affirmation des basileis aux dépens des anciens anaktes ${ }^{127}$. Faut-il exploiter davantage encore ce que tait le projet de Ménélas et faire de lui le fruit d'une nouvelle idéologie aristocratique prompte à sacrifier les fondements d'une monarchie en crise sur l'autel d'un compagnonnage égalitaire ${ }^{128}$ ? La tentation est grande, car Ménélas n'assied son projet ni sur les soubassements de la transmission héréditaire du pouvoir ni sur ceux de l'investiture divine. À trop vouloir cependant tirer conclusion des absences du texte, on risque fort de fondre le projet de l'Atride dans le moule trop parfait du prisme idéal.

La prudence exige de surtout retenir ce que désire explicitement Ménélas: transplanter Ulysse depuis Ithaque jusqu'en Argos. Apprécié à une échelle plus petite, son vœu pourrait ainsi faire écho à une autre dimension de la poliadisation du viII ${ }^{\mathrm{e}}$ siècle: l'essaimage des Grecs en Méditerranée. Le monde grec du haut archaïsme s'ouvre et l'Odyssée s'effraie sans doute de la mobilité accrue des siens. Les échos de la colonisation résonnent, nombreux, dans l'épopée homérique. Alors que Tlépolème accompagné d'un grand laos quitte son pays pour fonder une nouvelle communauté à Rhodes, Nausithoos transplante les Phéaciens à Schérie pour les éloigner des dangereux Cyclopes $^{129}$. Dans l'Odyssée, le rusé Ulysse agit en héros proto-colonial ${ }^{130}$ lorsque, confronté à l'Autre, il pèse les profits de la mise en exploitation de sa terre. Le projet de Ménélas pourrait prolonger cette liste d'allusions homériques à la colonisation, à condition toutefois d'être lu comme le miroir au négatif des expériences outre-mer ${ }^{131}$. À l'inverse des acistes grecs qui partent vers les périphéries méditerranéennes pour fonder, sur les côtes, des colonies d'abord modestes, Ménélas propose à Ulysse de quitter l'île périphérique d'Ithaque pour rejoindre l'intérieur du monde hérö̈que. Le fils de Laërte y trouvera richesses et concorde aristocratiques, alors que les colons cherchent souvent à tourner le dos au dénuement et aux troubles politiques qui minent leur cité d'origine. C'est bien encore l'ensemble des siens qui devront accompagner Ulysse dans une terre familière, peuplée de semblables. Les contingents partis à l'aventure s'extraient, quant à eux, de leur société d'origine, se mélangent à des colons venus d'autres cités et, une fois installés, doivent composer avec un Autre parfois agressif afin de façonner un corps social homogène. C'est bien enfin un monde ancien où prime le contact topographique que Ménélas propose à Ulysse, et non un univers nouveau qui, en mettant à distance les colonies avec leur cité mère, fait des réseaux la matrice de son identitéél ${ }^{32}$.

L'éclairage de la colonisation semble a priori faciliter la mise en correspondance de l'espace imaginé par Ménélas avec des réalités historiques du haut archaïsme. Trois hypothèses sont effectivement envisageables. L'Argos de Ménélas pourrait, par exemple, prendre le contre-pied de la colonie de Tarente ${ }^{133}$. Des Spartiates de naissance illégitime (les Parthéniens), incapables d'hériter, contraints dès lors à coloniser des terres à l'étranger où ils devront mener une guerre contre les indigènes... La tentation de lire le projet de Ménélas au négatif de la colonie spartiate s'impose cependant difficilement, car sa date de fondation (706) semble un peu trop tardive pour véritablement influer sur la composition de l'Odyssée. Des remarques comparables entament l'hypothèse

127 Sur cette question Descat 1979, 229-240; Lévy 1987, 291-314; Ndoye 2007, 73-84.

128 Notamment Carlier 1984, 213-214, 509, Schnapp-Gourbeillon 2002, 321-322 et Ndoye 2007, 84.

129 Homère, Iliade, II, 661-670 et Odyssée, VI, 4-10.

130 Voir ici Malkin 1998 et Malkin 2011, 213. Sur la mètis régulièrement prêtée à l'oikiste: M. Giangiulio 1981, 1-24.

\footnotetext{
131 Pour une synthèse récente sur la «colonisation» grecque: Schwentzel (dir.) 2012.

132 Sur les réseaux comme matrice de l'identité grecque à l'époque archaïque : Malkin 2011, 205-212.

133 Sur la colonie spartiate de Tarente, se référer notamment à Wuilleumier 1968 et Malkin 1999, 143171 .
} 
d'une mise en abyme du projet de l'Atride avec la colonisation de proximité dans le Péloponnèse ${ }^{134}$. Si, comme le montre I. Malkin, les Spartiates entreprennent de fonder, à leurs frontières et parfois grâce à des populations "non lacédémoniennes», des cités pour servir des objectifs stratégiques externes mais aussi pour résoudre des problèmes sociaux et politiques internes, leurs nouvelles implantations se développent seulement à partir de la seconde moitié du viII ${ }^{\mathrm{e}}$ siècle. Faut-il dès lors se tourner vers Olympie dont le développement a pu être porté par un sentiment panhellénique ${ }^{135}$ né en réaction à la dispersion des Grecs dans le monde méditerranéen? Centre de rencontre agonistique où les aristocrates venus de diverses cités aiment nouer provisoirement contact lors de jeux et de banquets, le sanctuaire ne prend cependant sa pleine dimension panhellénique qu'à partir du $\mathrm{VI}^{\mathrm{e}}$ siècle. Aux premiers temps de l'époque archaïque, il reste surtout un lieu de rencontre neutre pour une «transregional aristocracy» venue de Messénie et d'Arcadie ${ }^{136}$.

Des royautés fédérales, des cités nées d'un synœeisme, des colonies proches et lointaines, un sanctuaire panhellénique... les espaces historiques se bousculent, nombreux, pour prétendre inspirer le projet de Ménélas. Si aucun ne lui correspond exactement, tous lui restent cependant familiers. De leur nombre comme de leur diversité, il ne faudrait pas conclure au défaut du questionnement proposé. Le projet de Ménélas est le fils d'une époque de haute créativité politique qui recompose les spatialités et confronte les contemporains à ces nouvelles organisations spatiales. L'Argos de l'Atride ne cherche pas tant à refléter une réalité historique qu'à proposer un idéal susceptible d'apaiser les contradictions spatiales dans lesquelles le monde grec du haut archaïsme semble pris. D'un côté, de nouveaux contacts topographiques nés du synœeisme ou de la colonisation "proche». De l'autre, de récents contacts topologiques favorisés par le développement des royautés fédérales, l'émergence des sanctuaires interrégionaux et la mise en réseau des cités du monde méditerranéen. Entre eux, un projet idéal de Ménélas qui cherche à résoudre leur contradiction en implantant le lointain " au plus près ». Faire venir Ulysse jusqu’à Ménélas pour maintenir un contact constant et régulier, c'est en effet créer un contact topographique avec un aristocrate habituellement approché par le biais du réseau. Loin d'être rhétorique, la question de la synthèse entre les deux modes de contacts prend tout son sens dans le conflit idéologique, détecté par I. Morris, entre les «middling and elitist traditions» de la poésie archaïque ${ }^{137}$. Soutenus par des poètes tels qu'Hésiode, les metrioi privilégient la défense des valeurs civiques de la polis archaïque, comme la sobriété et la modération paysanne. En réaction à l'affirmation de la «middling tradition», les partisans de l' «elitist tradition» cherchent à tirer, par-delà la communauté locale, leur autorité de rapports aristocratiques établis entre cités et soutenus par le développement des sanctuaires interrégionaux. Héros de la communauté, des liens d'hospitalité et d'amitié, Ménélas doit sans doute chercher à concilier ces spatialités archaïques concurrentes : le proche et le local des metrioi, le lointain et les réseaux des aristocrates. Sa mission est d'importance, car il en va du maintien de la concorde et de la cohésion de communautés grecques confrontées à la question majeure d'une poliadisation archaïque qui se concrétise autant par le synœcisme que par la mise en réseau colonial.

\footnotetext{
134 Sur ce phénomène colonial: Malkin 1994, 106111.

135 Pour une discussion sur la force réelle du sentiment panhellénique à l'époque archaïque: Hall 2007, 270 .
}

\footnotetext{
136 Sur Olympie à l'époque archaïque, consulter notamment Hall 2007, 270-272 et Neer 2007, 225-248.

137 Morris 1996, 19-48.
} 


\section{Conclusion}

Ni strictement politique ni complètement ancré dans l'espace réel, le vœu de Ménélas consistant à transplanter Ulysse et les siens d'Ithaque à Argos s'apprécie d'abord à la lumière d'une géographie culturelle et relationnelle, attentive à la diversité des contacts décrits dans l'Iliade et l'Odyssée. En phase avec la conception de l'espace telle qu'elle peut s'exprimer dans l'iconographie des vases archaïques, Homère s'intéresse moins à la réalité géographique du monde qu'à la dimension symbolique de l'espace et des relations établies entre ses composantes. Pris dans une société qui se pense, se réalise et se construit, à toutes les échelles, par contact topographique immédiat, Ménélas cherche d'abord à faire d'Ulysse son voisin. Il en va de la force et de la pérennité de son amitié avec son compagnon tout comme du bon fonctionnement d'Argos, le brillant cœur du monde héroïque qu'il entend occuper. Terreau de la construction identitaire, la proximité spatiale assurée par contact topographique ou bien par des relations directes avec le monde extérieur conditionne effectivement la réalisation du projet de l'Atride. Perçu comme idéal, il ne tolère pas la discontinuité spatiale qui est toujours, dans le monde homérique, le signe et le moteur du dysfonctionnement social, politique et identitaire.

La logique du projet de Ménélas se comprend une fois replacée dans le contexte historique $\mathrm{du}$ haut archaïsme. Maîtriser la distance dans un monde perçu comme dangereux et infini relève d'un défi d'autant plus angoissant que l'essaimage force l'ouverture au monde d'entités locales en cours de poliadisation. Partir au loin, c'est non seulement risquer de se perdre dans l'inconnu mais aussi éprouver les liens communautaires sous le poids de la dispersion coloniale ${ }^{138}$. Confronté à un monde en mutation qui joue avec de nouvelles échelles et se couvre de réseaux, l'Odyssée accompagne les réflexions des contemporains sur la distance et tente sans doute, avec le vou de Ménélas, de proposer un projet susceptible de concilier les modes de contact alors en concurrence. Espace héroïque parfait, l'Argos de Ménélas n'a pas effectivement vocation à refléter un espace historique réel mais à guider les Grecs dans la construction de leur monde. Faut-il privilégier la grande ou la petite échelle pour construire une communauté ? Quels modes de contacts doit-on établir entre ses membres? Au service d'une épopée qui reflète moins l'histoire qu'elle n'en livre une philosophie ${ }^{139}$, l'idéalité spatiale proposée par Ménélas sert finalement les mêmes desseins que la royauté homérique, qui relève elle aussi moins d'une institution historique particulière que d'un type idéal ${ }^{140}$. Il faut accompagner les Grecs dans les mutations du haut archaïsme comme dans celles des siècles à venir et permettre ainsi de penser leur monde qui, depuis le système palatial mycénien jusqu'à la conquête romaine, n'a cessé d'hésiter entre l'unification politique et le maintien de l'autonomie locale. À l'instar des autres héros dont l'exemple doit garantir l'édification des générations futures, Ménélas propose, avec son projet idéal, un schème spatial utile pour orienter la construction des communautés grecques à venir.

Si cette perspective pourra consoler Ménélas incapable d'établir Ulysse auprès de lui, elle consacre surtout la réussite de l'aède. Non content d'inspirer l'harmonieux fonctionnement de l'Argos de Ménélas, l'espace de récitation poétique est encore conçu, dans l'Odyssée, comme le moteur de la société idéale. Ulysse assure ainsi à Alkinoos : "le plus cher de mes vœux, je te jure, est cette vie de tout un peuple en bon accord, lorsque dans les manoirs, on voit en longues files les convives sié-

138 D'après Malkin 2011, 211, le terme grec apoikia, utilisé plus tard pour désigner la colonisation, insiste justement sur l'idée de déchirement et sur le sentiment de «vivre à distance» de l'oikos (apoikein).
139 Sur cette idée Vlachos 1974, 22-23.

140 Voir ici notamment Lévy 1987, 291. 
ger pour écouter l'aède, quand, aux tables, le pain et les viandes abondent (...). Voilà, selon mon gré, la plus belle des vies!» ${ }^{141}$. Les intentions sont claires, les rôles distribués: c'est à l'aède de forger l'espace idéal et d'assurer la concorde civique. Espace de contact provisoire entre des voisins plus ou moins éloignés les uns des autres, le banquet concrétise les relations sociales tout en donnant cohérence à l'espace communautaire. Permettre à son auditoire d'honorer le vœu de Ménélas, c'est non seulement le placer, par cette mise en abyme réactivée à chaque récitation poétique, dans une posture héroïque mais aussi et surtout le convaincre que l'aède est l'architecte indispensable au bonheur de la communauté.

\section{BIBLIOGRAPHIE}

Andreev, J. V., 1979, «Könige und Königsherrschaft in den Epen Homers», Klio 61, 361-384.

Bakker, E. J., 2013, The Meaning of Meat and the Structure of the Odyssey, Cambridge: Cambridge University Press.

Ballabriga, A., 1986, Le soleil et le Tartare. L'image mythique du monde en Grèce archaïque, Paris: Éditions de l'EHESS.

—, 1998, Les fictions d'Homère. L'invention mythologique et cosmographique dans l'Odyssée, Paris: PUF.

Bertrand, J.-M., 1997, Cités et royaumes du monde grec : espace et politique, Paris: Hachette.

BÉrard, V., 1927-1929, rééd. 1971, Les navigations d'Ulysse, Paris: Armand Colin.

BoËLdieu-Trévet, J., 2007, Commander dans le monde grec au ve siècle avant notre ère, Besançon: Bréal.

Bouvier, D., 1986, "La tempête de la guerre. Remarques sur l'heure et le lieu du combat dans l'Iliade», Mètis $\mathrm{I}: 2,237-257$.

Bouvier, D., 2002, Le sceptre et la lyre. L'Iliade ou les héros de la mémoire, Grenoble: Éditions Jérôme Millon.

Briand, M., 1998, «Stratégies discursives et jeux d'identités dans le chant IV de l'Odyssée», in: P. SAUZEAU (éd.), Télémaque et l'Odyssée, Montpellier: Université Paul Valéry, 27-55.

Broodbank C., 2013, The Making of the Middle Sea: A History of the Mediterranean from the Beginning to the Emergence of the Classical World, Oxford - New York: Oxford University Press.

Calame, C., 2007, «L'Odyssée entre fiction poétique et manuel d'instructions nautiques », L'Homme 181, 151-172.

Cantarella, E., 2002, 2003, Ithaque. De la vengeance d'Ulysse à la naissance du droit, Paris: Albin Michel.

CARLIER, P., 1984, La royauté en Grèce avant Alexandre, Strasbourg: AECR.

Casevitz, M., 1998, «Remarques sur l'histoire de quelques mots exprimant l'espace en grec», REA 100(3-4), 417-435.

Christien, J. et RuzÉ, F., 2007, Sparte. Géographie, mythes et histoire, Paris: Armand Colin.

Collobert, C., 2011, Parier sur le temps. La quête hérö̈que d'immortalité dans l'épopée homérique, Paris: Les Belles Lettres.

Coquin, M.-J., 2007, «Laos / stratos et laos-dèmos : remarques sur les noms de l'armée et du peuple dans l'Iliade», Ktèma 32, 459-465.

Daude, C., 2007, «Pourquoi je crois que, tout compte fait, Homère ne désapprouve pas la colère d'Achille», in Troïka. Parcours antiques. Mélanges offerts à Michel Woronoff, tome I, Besançon: PUFC, 39-62.

141 Homère, Odyssée, IX, 5-11 avec P. Demont, La cité grecque archä̈que et classique et l'idéal de la tranquil-

lité, Paris, 1990, p. 33. 
Demont, P., 1990, La cité grecque archaïque et classique et l'idéal de la tranquillité, Paris: Les Belles Lettres.

Descat, R., 1979, «L'idéologie homérique du pouvoir», REA 81, 229-240.

Duplouy, A., 2006, Le prestige des élites. Recherche sur les modes de reconnaissance sociale en Grèce entre les $X^{e}$ et $V^{e}$ siècles avant J.-C., Paris: Les Belles Lettres.

Étienne, R., Müller C. et Prost F., 2000, Archéologie historique de la Grèce antique, Paris: Ellipses.

Étienne, R., 2010, «Historiographie, théories et concepts», in: R. Étienne (dir.), La Méditerranée au VII s. av. J.-C., Paris: Travaux de la Maison René Ginouvès, 3-26.

Fanta, A., 1882, Der Staat in Der Ilias und Odyssee, Innsbruck: German Editions.

Finley, M. I., 1954, 1977, Le Monde d'Ulysse, Paris: Maspero.

Frontisi-Ducroux, F., 1995, Du masque au visage. Aspects de l'identité en Grèce ancienne, Paris: Flammarion.

Frontisi-Ducroux, F.et Vernant, J.-P., 1997, Dans l'œeil du miroir, Paris: Éditions Odile Jacob.

Giangivlio, M., 1981, "Deformita eroiche e tradizioni di fondazione. Batto, Miscello l'oracolo delfico», Annali della Scuola Normale Superiore di Pisa 3:11, 1-24.

Hall, J. M., 2007, A History of the Archaic Greek World, ca. 1200-479 BCE, Oxford: Blackwell.

Hartog, F., 1982, "Des lieux et des hommes», in Homère, Odyssée, traduction Ph. Jaccottet, Paris, 415428.

Hartog, F., 1996, Mémoire d'Ulysse. Récits sur la frontière en Grèce ancienne, Paris: Gallimard.

Heubeck, A., West, S. et Hainsworth, J. B., 1990, A Commentary on Homer's Odyssey, I, Oxford: Oxford University Press.

Horden P., et Purcell, N., 2000, The Corrupting Sea : a Study of Mediterranean History, Oxford: Blackwell Publishers.

ЈАСОВ, С., 1990, Géographie et ethnographie en Grèce ancienne, Paris: Armand Colin.

Jacquet-Rimassa, P., 2002, «Essai de mise au point: la représentation de l'habitat et de l'architecture dans l'imagerie archaïque», Pallas 58, 117-145.

Jeanmaire, H., 1939, Couroi et courètes. Essai sur l'éducation spartiate et les rites d'adolescence dans l'Antiquité hellénique, Lille: Thèse de doctorat.

Kakridis, H. J., 1963, La notion de l'amitié et de l'hospitalité chez Homère, Thessalonique.

Karavites, P., 1992, Promise-giving and Treaty-Making. Homer and the Near East, Leiden: E. J. Brill.

Lateiner, D., 1992, "Heroic Proxemics: Social Space and Distance in the Odyssey», TAPhA 122, 133163.

Larran, F., 2011, Le bruit qui vole. Histoire de la rumeur et de la renommée en Grèce ancienne, Toulouse: PUM.

Levaniouk, O., 2011, Eve of the Festival. Making Myth in Odyssey 19, Washington D.C.: Center for Hellenic Studies.

LÉvy, Ed., 1987, «Lien personnel et titre royal: anax et basileus dans l'Iliade», in: Ed. Lévy (éd.), Le système palatial en Orient, en Grèce et à Rome. Actes du colloque de Strasbourg, 19-22 juin 1985, Strasbourg: E. J. Brill, 291-313.

—, 1995, "Arétè, timè, aidôs et némésis: le modèle homérique», Ktèma 20, 177-211.

Lévy, J. et Lussault, M. (dir.), 2000, Logiques de l'espace, esprit des lieux. Géographies à Cerisy, Paris: Belin.

Lowenstam, S., 1993, The Scepter and the Spear. Studies on Forms of Repetition in the Homeric Poems, Lanham: Rowman \& Littlefield.

Lussault, M., 2007, L'homme spatial. La construction sociale de l'espace humain, Paris: Seuil.

Malkin, I., 1998, The Returns of Odysseus. Colonization and Ethnicity, Berkeley: University of California Press.

—, 1994, 1999, La Méditerranée spartiate. Mythe et territoire, Cambridge, Paris: Les Belles Lettres.

—, 2005, "Networks and the Emergence of Greek Identity», in: I. Malkin (éd.), Mediterranean Paradigms and Classical Antiquity, Londres et New York: Routledge, 56-73. 
Malkin, I., 2011, A Small Greek World. Networks in the Ancient Mediterranean, New York-Oxford: Oxford University Press.

Morris, I., 1996, "The Strong of Equality and the Archaic Origins of Greek Democracy», in: J. Ober et C. Hedrick (éds.), Demokratia. A conversation on Democracy, Ancient and Modern, Princeton: Princeton University, 19-48.

NaAs, M., «Le tournant de l'amitié chez Homère», Tympanum 4 : Khoraographies for Jacques Derrida, 15 juillet, 2000 (on line journal at http://www.edu/tympanum/4/).

Ndoye, M., 2007, "Grandeur et décadence des anaktes dans les poèmes homériques», in: Trö̈ka. Parcours antiques. Mélanges offerts à Michel Woronoff, I, Besançon: PUFC, 73-84.

Neer, R. T., 2007, «Delphi, Olympia, and the Art of Politics», in: H. A. Shapiro, The Cambridge Companion to Archaic Greece, Cambridge, Cambridge University Press, 225-248.

Osborne, R., 1998, "Early Greek Colonisation? The Nature of Greek Settlements in the West», in: N. Fisher et H. van Wees (éds.), Archaic Greece. New Approaches and New Evidence, Londres: Duckworth, 251-269.

Pucci, P., 1995, Ulysse polutropos. Lectures intertextuelles de l'Iliade et de l'Odyssée, Lille: Presses Universitaires du Septentrion.

Purcell, N., 1990, 1992, «La mobilité et la polis», in: O. Murray et S. Price (éds.), La cité grecque d'Homère à Alexandre, New York, Paris, La Découverte. 43-78.

Rabau, S., 2005, "Contributions à l'étude du complexe de V. Bérard : sur une lecture référentielle de l'Odyssée», Lalies 25, 111-126.

Riedinger, J.-C., 1976, «Remarques sur la timè chez Homère», REG 89, 244-264.

Rougemont, F., 2009, Contrôle économique et administration à l'époque des palais mycéniens. Fin du Ile millénaire avant J.-C., Paris: De Boccard.

Rougier-Blanc, S., 2002, «Maisons modestes et maisons de héros chez Homère. Matériaux et techniques», Pallas 58, 101-116.

—, 2007, «Lieux d'audience et rituel chez Homère», in: J.-P. Caillet et M. Sot (dir.), L'audience : rituels et cadres spatiaux dans l'Antiquité et le Haut Moyen Âge, Paris: Picard, 49-75.

Rousseau, Ph., 1990, «Le deuxième Atride. Le type épique de Ménélas dans l'Iliade», in: Mélanges offerts à Pierre Lévêque, 5, Besançon: PUFC, 325-354.

—, 1992, «Remarques complémentaires sur la royauté de Ménélas », in: M. Woronoff, L'univers épique, Paris-Besançon: PUFC, 57-79.

RuzÉ, F., 1989, «Basileis, tyrans et magistrats», Mètis 4, 211-231.

—, 1997, Délibération et pouvoir dans la cité grecque de Nestor à Socrate, Paris: Publications de la Sorbonne.

SAÏD, S., 1998, Homère et l'Odyssée, Paris: Belin.

Sauzeau, P., 2004, «Pourquoi Argos nourrit-elle des cavales?», Pallas 64, 129-143.

—, 2005, Les partages d'Argos. Sur les pas des Danaïdes, Paris: Belin.

Scheid-Tissinier, É., 1988, Etude sur le vocabulaire et les pratiques du don chez Homère, Paris: Thèse de doctorat.

—, 1999, L'homme grec aux origines de la cité (900-700 av.), Paris: Armand Colin.

—, 2002, "Laos et dèmos, le peuple de l'épopée», $A C 71,1-26$.

Schnapp-Gourbeillon, A., 2002, Aux origines de la Grèce, XIII'-VIII siècles avant notre ère. La genèse du politique, Paris Les Belles Lettres.

Schwentzel, C.-G. (dir.), Dana M., Lebreton S. et Prêteux F., 2012, Les diasporas grecques, VIII ${ }^{e}-I{ }^{e}$ siècles, Paris: Atlande.

Sebillotte Cuchet, V., 2006, Libérez la patrie! Patriotisme et politique en Grèce ancienne, Paris: Belin.

SERgent, B., 1994, «Les sept cités promises à Achille: de quoi parle-t-on?», RA, 103-109.

Vidal-Naquet, P., 1970, «Valeurs religieuses et mythiques de la terre et du sacrifice dans l'Odyssée», Annales ESC 25, 1278-1297.

Vilatte, S., 1991, L’insularité de la pensée grecque, Paris: Les Belles Lettres. 
Visser, E., 1997, Homers Katalog der Schiffe, Stuttgart: B. G. Teubner.

VLAChOS, G. C., 1974, Les sociétés politiques homériques, Paris: PUF.

Wathelet, P., 1992, «Argos et l'Argolide dans l'épopée, spécialement dans le Catalogue des vaisseaux», in: M. Piérart (éd.), Polydipsion Argos: Argos de la fin des palais mycéniens à la constitution de l'État classique: actes de la table ronde Fribourg (Suisse), 7-9 mai 1987, Paris: BCH.

Whitman, C. H., 1965, Homer and the Heroic Tradition, New York: The Norton Library.

Wuilleumier, P., 1939, 1968, Tarente: des origines à la conquête romaine, Paris: De Boccard. 